\title{
EFEKTIVITAS PROGRAM USAHA PENINGKATAN PENDAPATAN KELUARGA SEJAHTERA (UPPKS) KELOMPOK MEKAR LESTARI KECAMATAN SEKUPANG KOTA BATAM
}

\section{EFFECTIVENESS OF BUSINESS PROGRAM FOR IMPROVING PROSPEROUS FAMILY INCOME (UPPKS) GROUP OF MEKAR LESTARI DISTRICT SEKUPANG, BATAM CITY}

\author{
A. Syaifullah ${ }^{1}$, Linayati Lestari ${ }^{2}$ \\ ${ }^{1}$ (Prodi Ilmu Pemerintahan, Fakulta Ilmu Sosial \& Ilmu Politik, Universitas Riau Kepulauan, Indonesia) \\ ${ }^{2}$ (Prodi Ilmu Pemerintahan, Fakultas Ilmu Sosial \& Ilmu Politik, Universitas Riau Kepulauan, Indonesia) \\ 'asyaifullah@gmailcom, ${ }^{2}$ linayatilestari@,yahoo.com
}

\begin{abstract}
Abstrak
Program Usaha Peningkatan Pendapatan Keluarga Sejahtera (UPPKS) merupakan program pemerintah non departemen oleh Badan Kependudukan dan Keluarga Berencana Nasional (BKKBN), tujuan penelitian ini untuk mengetahui Efektivitas Program Usaha Peningkatan Pendapatan Keluarga Sejahtera (UPPKS) di kelompok Mekar Lestari Kecamatan Sekupang Kota Batam Tahun 2016. Adapun metode yang digunakan dalam penelitian ini adalah metode penelitian kualitatif.Subyek penelitian ini adalah Kasubid pemberdayaan ekonomi keluarga BKKBN Kepulauan Riau, Pengurus dan anggota kelompok UPPKS Mekar Lestari, serta Masyarakat sekitar.Sedangkan Obyek penelitian ini adalah melihat efektif tidaknya program UPPKS yang dijalankan oleh kelompok Mekar Lestari Kecamatan Sekupang, Kota Batam.Pengumpulan data dalam penelitian ini menggunakan teknik observasi, wawancara, dan dokumentasi.Adapun teknik analisis yang digunakan adalah menggunakan analisis data yang terdiri dari reduksi data, penyajian data, dan penarikan kesimpulan. Hasil penelitian ini menunjukan bahwa efektivitas program Usaha peningkatan Pendapatan Keluarga Sejahtera di Kelompok Mekar Lestari Kecamatan Sekupang Kota Batam sudah berjalan dengan efektif, ditandai dengan para anggotanya yang mendapatkan keuntungan dari hasil usaha masing - masing anggota UPPKS. Program UPPKS ini juga terbukti memberikan banyak manfaat dikelompok Mekar lestari seperti meningkatan ekonomi keluarga bagi para anggotanya dengan mengembangkan usaha ekonomi produktif dalam meningkatkan taraf pendapatan keluarga. Akan tetapi, program yang belum efektif yaitu pada pemahaman mengenai akan maksud dan tujuan dibentuknya program UPPKS bagi para anggota UPPKS karena kurangnya sosialisasi dari pihak penyelenggara program.
\end{abstract}

\section{Kata Kunci : Efektivitas, UPPKS, Kesejahteraan Masyarakat}

\begin{abstract}
Prosperous Family Income Improvement Program (PFIIP / UPPKS) is a non-departmental government program by the National Population and Family Planning (BKKBN), the prupose of this study was to determine the effectiveness of the Welfare Family Income Improvement Business Program (UPPKS) in the Mekar Lestari group in Batam City Sekupang District in 2016. The method used in this research is qualitative research methods. The subjects of this study were the Head of Subdivision of the family empowerment of the Riau Islands $B K K B N$, Management and members of the Mekar Lestari UPPKS group, and the surrounding community. While the object of this research is to see the effectiveness of the UPPKS program carried out by the Mekar Lestari group in Sekupang District, Batam City. Data collection in this study uses observation, interview, and documentation techniques. The analysis technique used is using data analysis consisting of data reduction, data presentation, and conclusion drawing. The results of this study indicate that the effectiveness of the Prosperous Family Income Business program in the Mekar Lestari Group, Sekupang Sub-District, Batam City, addresses some that have been effective. The UPPKS program is said to be effectively marked by its members who benefit from the results of the efforts of each member of the UPPKS. The UPPKS program is also proven to provide many benefits to the sustainable Bloomers group such as increasing the family economy for its members by developing productive economic enterprises in increasing the level of family income. The program is said to have not been effective in understanding the program regarding the purpose and objectives of the UPPKS program for members of the UPPKS due to the lack of socialization from the program organizers.
\end{abstract}

Keywords: Effectiveness,UPPKS, Public Welfare 


\section{PENDAHULUAN}

Di Indonesia kemiskinan merupakan suatu ancaman yang ada sejak Negara Kesatuan Republik Indonesia (NKRI) ini berdiri.Terjadinya krisis moneter pada tahun 1997 semakin memperparah kondisi kemiskinan yang telah ada sebelumnya.Sejak tahun ini krisis menjadi pintu gerbang dari segala permasalahan.Dalam perkembangannya krisis yang terjadi akhirnya membawa dampak buruk terhadap perekonomian Indonesia.Inflasi yang melonjak ke tingkat yang lebih tinggi, pengaruhnya adalah harga-harga kebutuhan pokok menjadi proporsional terhadap inflansi yang sedang terjadi.Pada akhirnya harga tersebut melebihi batas kemampuan daya beli sebagian masyarakat Indonesia.Dalam banyak kasus kemiskinan diawali dari kurangnya akses tenaga kerja produktif terhadap lapangan pekerjaan yang tersedia (Muhammad Yunus, 2008). Kemiskinan merupakan keadaan dimana tingkat pendapatan seseorang tidak mencukupi untuk memenuhi kebutuhan pokok seperti: sandang, pangan, pemukiman, kesehatan dan pendidikan. Masalah kemiskinan sampai saat ini masih terus-menerus menjadi permasalahan penting di Indonesia penduduk miskin pada umumnya tidak berdaya atau kurang memiliki ketrampilan agar dapat mengembangkan diri menuju pada taraf sejahtera (Suyanto, 2013).

Permasalahan umum yang terjadi pada semua penduduk miskin adalah masalah keuangan. Penduduk miskin identik dengan jumlah pendapatan yang hanya cukup atau tidak cukup untuk memenuhi kebutuhan sehari-hari. Masalah keuangan terbentuk ketika banyaknya kebutuhan sehari-hari yang tidak dapat terpenuhi seperti : defisit anggaran belanja, ketidakmampuan untuk menabung, terjerat hutang dan lain sebagainya. Hal ini berkembang menjadi suatu krisis keuangan ketika hasil pendapatan individu atau keluarga tidak dapat mencukupi pengeluaran yang mendasar (Silalahi, 2010). Salah satu indikator yang tak pernah lepas dari perhatian pemerintah adalah kemiskinan.Penduduk termasuk dalam kategori miskin apabila pengeluaran per bulannya berada di bawah garis kemiskinan.Garis kemiskinan untuk Kota Batam selalu mengalami kenaikan seiring dengan perubahan harga komoditas barang dan jasa. 
Tabel 1.1 : Garis Kemiskinan Menurut Kabupaten/Kota di Provinsi Kepulauan Riau Tahun 2013-2016

\begin{tabular}{|l|c|c|c|c|}
\hline \multirow{2}{*}{ Nama Wilayah } & \multicolumn{4}{|c|}{ Garis Kemiskinan Menurut Kabupaten/Kota } \\
& \multicolumn{4}{|c|}{ (Rupiah/Kapita/Bulanan) } \\
\cline { 2 - 5 } & $\mathbf{2 0 1 3}$ & $\mathbf{2 0 1 4}$ & $\mathbf{2 0 1 5}$ & $\mathbf{2 0 1 6}$ \\
\hline Karimun & 288856 & 299538 & 309558 & 338341 \\
\hline Bintan & 298916 & 301829 & 313277 & 341812 \\
\hline Natuna & 264855 & 267150 & 276828 & 302043 \\
\hline Lingga & 338049 & 342359 & 354916 & 387244 \\
\hline Kepulauan Anambas & 268570 & 271539 & 313042 & 341556 \\
\hline Batam & 482567 & 497415 & 525452 & 565380 \\
\hline Tanjung Pinang & 506647 & 514741 & 542857 & 582414 \\
\hline
\end{tabular}

Sumber : Badan Pusat Statistik Provinsi Kepulauan Riau, 2017.

Dari tabel tersebut garis kemiskinan untuk provinsi Kepulauan Riau terus mengalami peningkatan setiap tahunnya. Begitu juga di setiap kabupaten kota juga mengalami peningkatan. Pada tahun 2013, garis kemiskinan Kota Batam sebesar Rp 482.567,-per kapita per bulan.Dengan besaran garis kemiskinan tersebut, terdapat sebanyak 57.519orang penduduk yang termasuk dalam kategori miskin. Indikator kemiskinan yang lainnya adalah indeks kedalaman kemiskinan dan indeks keparahan kemiskinan.Indeks kedalaman kemiskinan menunjukkan rata-rata kesenjangan pengeluaran masing-masing penduduk miskin terhadap garis kemiskinan. Kepedulian pemerintah dalam upaya penanggulangan kemiskinan diwujudkan dengan adanya beberapa kebijakan pemberdayaan ekonomi bagi keluarga miskin yang diprogramkan pemerintah sebagai salah satu langkah yangefektif dalam upaya penanggulangan kemiskinan baik melalui kelembagaan yang bersifat lembaga departemen maupun non departemen.

Salah satunya adalah Badan Kependudukan dan Keluarga Berencana Nasional (BKKBN) yang menyelenggarakan program Usaha Peningkatan Pendapatan Keluarga Sejahtera (UPPKS) sebagai program pemberdayaan ekonomi keluarga. Program UPPKS ini merupakan program pemerintah untuk membantu keluarga miskin dalam meningkatkan pendapatan keluarga.Masalah utama yang menjadi kendala terbesar dalam keluarga adalah peningkatan kesejahteraan.Kesejahteraan keluarga merupakan keadaan dimana beberapa kebutuhan yang harus dipenuhi dalam kehidupan sehari-hari.Untuk dapat memenuhi kebutuhan yang terus mendesak uang merupakan faktor yang paling utama dalam mencapai tujuan kehidupan (Hikmat, 2010). 
Program Usaha Peningkatan Pendapatan Keluarga Sejahtera (UPPKS) merupakan program yang pelaksanaannya diintegrasikan dengan program Keluarga Berencana(KB), yang bertujuan untuk meningkatkan usahaekonomi produktif dan keterampilan terutama untuk keluargayang tergabung dalam kelompok UPPKS sedangkan yang menjadi tujuan khusus di bentuknya kelompok UPPKS ini adalah : 1). Meningkatnya jumlah modal usaha untuk mengembangkan kelompok UPPKS; 2). Meningkatnya jumlah kelompok UPPKS yang mempunyai modal usaha; 3). Meningkatnya jumlah anggota kelompok yang berusaha; 4). Meningkatnya kualitas usaha kegiatan kelompok;dan 5) meningkatnya kesejahteraan keluarga khususnya keluarga prasejahtera dan keluarga sejahtera I (keluarga miskin).

Tanpa kondisi ekonomi yang baik, mustahil keluarga akan dapat meningkatkan kualitas kehidupan. Kegiatan usaha ini telah dirintis dan dipelopori oleh BKKBN yang merupakan model usaha mikro keluarga yang berfungsi untuk menggerakkan roda ekonomi keluarga melalui pembelajaran usaha ekonomi dengan cara menggugah minat dan semangat keluarga untuk berwirausaha.Untuk mengembangkan kelompok UPPKS(Usaha Peningkatan Pendapatan Keluarga Sejahtera)ini banyak kegiatan yang telah dilakukan oleh pemerintah yang dimotori oleh BKKBN : Kegiatan-kegiatan tersebut antara lain 1. Memberikan bantuan fasilitas permodalan kepada kelompok yang meliputi danabergulir, dana BUMN, Kukesra, Kredit Pengembangan Kemitraan Usaha (KPKU), dan Kukesra Mandiri; 2. Pembinaan dan pengembangan usaha kelompok UPPKS melaluikegiatan peningkatan kualitas Sumber Daya Manusia (SDM) yang terlibat dalam kegiatan tersebut, pembinaan kemitraan baik dalam hal permodalan, SDM, produksi, manajemen usaha, penerapan teknologi tepat guna dan pemasaran;3. Pembinaan jaringan usaha yang bertujuan untuk meningkatkan akses anggota kelompok ini dengan berbagai pihak; 4.Pembinaan produksi agar kelompok UPPKS menghasilkan produk, baik kuantitas maupun kualitas, yang sesuai dengan permintaan pasar (BKKBN, 2005).

Namun dalam pelaksanaan program usaha peningkatan pendapatan keluarga sejahtera (UPPKS) kelompok mekar lestariini masih belum berjalan dengan baik, Sebab adanya kendala pada pelaksanaannya seperti harga produk kerajinanyang dihasilkan ketika dipasarkan oleh kelompok UPPKS Mekar Lestari relatif lebih mahal daripada pedagang lain, dikarenakanharga-harga dari produk yang dihasilkan kelompok dari bahan baku, biaya operasional, dan tenaga dilakukan secara mandiri, serta produk yang dipasarkan terutama dari produk makanan masih belum bersertifikat halal dari majelis ulama Indonesia, hal ini 
dikarenakan biaya untuk mendaftarkan produk agar bersertifikat halal relatif mahal. Sebab itulah kebanyakan tampilan kemasan produk yang dihasilkan oleh pelaku usaha di Kelompok UPPKS Mekar Lestari lebih menekankan keunggulan produk tersebut dibandingkan cara pengemasannya dan belum ada penjelasan mengenai nilai gizi di dalam kemasannya.

Penjelasan yang diterima konsumen kurang lengkap dan pemahaman konsumen akan produk tersebut juga kurang. Sehingga konsumen kurang tertarik dengan produk tersebut, biasanya konsumen memutuskan untuk membeli suatu produk berdasarkan informasi yang dicantumkan pada kemasan produk tersebut.Kendala lainnya yaitu masih kurangnya waktu bagi anggota kelompok untuk memenuhi pesanan mendadak dari konsumen seperti pesanan kue, hal ini disebabkan oleh kesibukan masing masing para anggota terhadap aktivitas sehariharinya.Secara umum kendala dalam pengembangan kelompok UPPKS ini yaitu kualitas sumber daya Manusia yang relatif rendah, seperti lemahnya motivasi untuk melakukan kegiatan usaha, rendahnya pengetahuan dan keterampilanlemah dalam aspek usaha yang meliputi aspek permodalan, pemanfaatan teknologi, dan pemasaran hasil usaha.

Berdasarkan dari paparan di atas, peneliti merasa tertarik untuk melihat bagaimana efektivitas pelaksanaan program usaha peningkatan pendapatan keluarga sejahtera (UPPKS) kelompok Mekar Lestari. Peneliti beralasan memilih kelompok ini sebab dari sekian banyak kelompok yang ada di Kota Batam, kelompok ini merupakan salah satu kelompok terbaik di Kepri, hal ini dapat dilihat dengan diraihnya juara 2 tingkat nasional,dimana Kepri diwakilkan oleh salah satu anggota kelompok Mekar Lestari yang diadakan di Banten dan juga dibuktikan dengan banyaknya sertifikat penghargaan yang didapat oleh kelompok UPPKS Mekar Lestari ini. Peneliti mengambil tahun 2016 agar bisa menilai efektivitas Program yang telah berjalan sebab penelitian ini dibuat tahun 2017, sedangkan kota Batam sebagai lokasi penetian karena Kota Batam merupakan Kota tebesar serta pusat perekonomian di provinsi Kepri.Kecamatan sekupang sebagai fokus penelitian karena ketika observasi awal dari tiga kelompok UPPKS yang ada di Kecamatan Sekupang hanya satu yang masih bertahan sampai sekarang, karena itu peneliti mengangkatnya dalam sebuah penelitian yang berjudul "Efektivitas pelaksanaan program usaha peningkatan pendapatan keluarga sejahtera (UPPKS) kelompok mekar lestari Kecamatan Sekupang Kota Batam Tahun 2016.

\section{METODOLOGI}

Jenis Penelitian yang digunakan peneliti dalam penelitian ini adalah metode deskriptif kualitatif. Penelitian ini mengambil lokasi di Kelurahan Patam Lestari pada Kelompok Mekar 
Lestari yang merupakan kelompok yang telah mengirimkan hasil Kerajinan Melalui BKKBN Provinsi Kepulauan Riau dalam rangka pameran di Bandung dan Provinsi Banten di Serang dan mendapat juara. Teknik analisis data melalui wawancara, dokumentasi, dan observasi langsung dilapangan.Berikut daftar Informan dalam penelitian ini :

Tabel 1.2 : Data Informan Penelitian

\begin{tabular}{|c|l|c|c|c|}
\hline No. & Nama Responden & Alamat & Pendidikan & Keterangan \\
\hline 1. & Dyana Poppylaya & Batam Centre & S2 & Kabid PEK \\
\hline 2. & Jami Kasto & Sekupang & S1 & Ketua \\
\hline 3 & Tri Suyati & Sekupang & SMA & Anggota \\
\hline 4 & Wahyu Dwi S. & Sekupang & S1 & Anggota \\
\hline 5 & Poniati Ningsih & Sekupang & SMA & Anggota \\
\hline 6 & Nangiman & Sekupang & SMA & Anggota \\
\hline 7 & Apriwati & Sekupang & S1 & Anggota \\
\hline 8 & F. Bazmara & Sekupang & SMA & Anggota \\
\hline 9 & Marleni & Sekupang & SMA & Anggota \\
\hline 10 & Siti Parlina & Sekupang & SMA & Masyarakat \\
\hline 11 & Rettuati & Sekupang & SMA & Masyarakat \\
\hline 12 & Cik Ayu & Sekupang & SMA & Masyarakat \\
\hline
\end{tabular}

\section{PEMBAHASAN}

\section{Pemahaman Program}

Pemahaman berasal dari kata paham yang mempunyai arti mengerti benar, sedangkan pemahaman merupakan proses pembuatan cara memahami. Pemahaman berasal dari kata paham yang artinya (1) pengertian; pengetahuan yang banyak, (2) pendapat, fikiran, (3) aliran; pandangan, (4) mengerti benar, apabila mendapat imbuhan me-i menjadi memahami, berarti mengetahui benar sehingga dapat diartikan bahwa pemahaman adalah suatu proses, cara memahami, cara mempelajari baik-baik supaya paham dan mengetahui banyak.Dalam hal indikator efektivitas pemahaman program masih belum efektif karena hanya penyelenggara program dan ketua kelompok saja yangcukup paham akan Maksud dan tujuan program UPPKS ini, sedangkan seacara konsep para anggotanya masih kurang paham akan tujuannya yang di sebabkan kurangnya sosialisasi oleh pihak Penyelenggara program dan ini bisa dilihat ketika pertemuan bulanan pihak dari PLKB tidak pernah hadir bersama keompok mekar lestari serta jika ada sosialisasi hanya untuk ketuanya saja dan itupun secara informal jika pihak BKKBN bertemu di acara acara tertentu dengan ketua kelompok mekar lestari. 


\section{Ketepatan Sasaran}

Ketepatan sasaran atau tepat sasaran berarti semakna dengan tepat guna, alias efektif, dalam hal penelitian ini ketepatan sasaran yang dimaksud adalah ketepatan dalam penetapan kelompok masyarakat yang dijadikan peserta dalam program Usaha peningkatan pendapatan keluarga sejahtera di kelompok mekar Lestari.

Tabel 1.3 : Data Anggota UPPKS Mekar Lestari yang ber KB dan yang mempunyai usaha

\begin{tabular}{|c|l|c|c|c|}
\hline No. & \multicolumn{1}{|c|}{ Nama } & Ikut KB & Produk & Keterangan \\
\hline 1 & Jami Kasto & - & Kerajinan & Lanjut Usia \\
\hline 2 & Nagiman & $\square$ Ya & Kerajinan & PSU \\
\hline 3 & Apriwati & - & - & Remaja \\
\hline 4 & Dwi Putri & $\square$ Ya & Aksesoris & PSU \\
\hline 5 & P. Bazmara & $\square$ Ya & Menjahit & PSU \\
\hline 6 & Poniati Ningsih & $\square$ Ya & Menjahit & PSU \\
\hline 7 & Dwi Wahyu & - & Jamu & Lanjut Usia \\
\hline 8 & Marleni & $\square$ Ya & - & PSU \\
\hline 9 & Ratna Wati & $\square$ Ya & - & PSU \\
\hline 10 & Tri Suryati & - & Makanan & Lanjut Usia \\
\hline
\end{tabular}

\section{Ketepatan Waktu dan Tercapainya Tujuan}
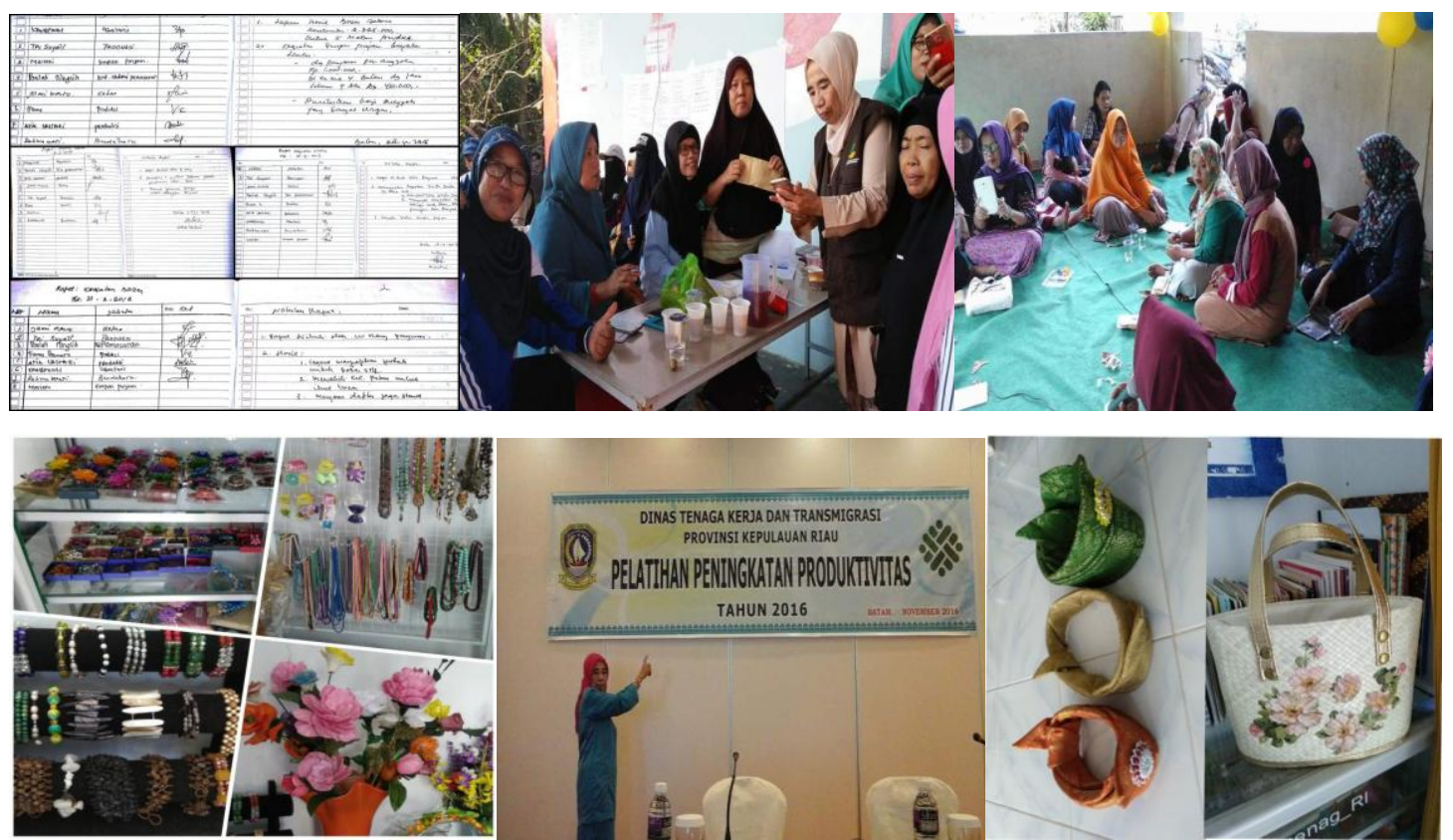

\section{Perubahan Nyata}

Tabel 1.4 : Perubahan pada anggota UPPKS Mekar Lestari sebelum dan sesudah bergabung 


\begin{tabular}{|c|l|l|}
\hline No. & \multicolumn{1}{|c|}{$\begin{array}{c}\text { Sebelum Menjadi Anggota } \\
\text { UPPKS }\end{array}$} & \multicolumn{1}{c|}{$\begin{array}{c}\text { Sesudah Menjadi Anggota } \\
\text { UPPKS }\end{array}$} \\
\hline 1. & $\begin{array}{l}\text { Ibu-Ibu kesulitan memasarkan } \\
\text { produk karena kurangnya Link } \\
\text { atau rekan dalam mempromosikan } \\
\text { produk mereka. }\end{array}$ & $\begin{array}{l}\text { Para anggota sudah mendapat } \\
\text { kemudahan dalam pemasaran } \\
\text { produk-produk mereka karena } \\
\text { banyaknya informasi dari rekan- } \\
\text { rekan satu kelompok tentang } \\
\text { pemasaran. }\end{array}$ \\
\hline 2. & $\begin{array}{l}\text { Masih rendahnya pengetahuan } \\
\text { untuk menciptakan produk- } \\
\text { produk yang bisa besaing } \\
\text { dipasaran karena tidak pernah } \\
\text { adanya pelatihan dan hanya } \\
\text { dikerjakan sendiri. }\end{array}$ & $\begin{array}{l}\text { Dengan adanya pelatihan baik } \\
\text { oleh ketua kelompok sendiri } \\
\text { dalam pertemuan rutin maupun } \\
\text { dari pemerintah dengan hal ini } \\
\text { menambah pengetahuan } \\
\text { mereka3.dalam menciptakan } \\
\text { produk b4.aru yang lebih bisa } \\
\text { bersaing dipasaran, seperti } \\
\text { kemasan yang cukup menarik. }\end{array}$ \\
\hline 3. & $\begin{array}{l}\text { Ekonomi keluarga masih belum } \\
\text { memadai hal ini dapat dilihat dari } \\
\text { belanja bulanan anggota yang } \\
\text { selalu kurang karena hanya } \\
\text { bergantung pada pendapatan } \\
\text { suami. }\end{array}$ & $\begin{array}{l}\text { Sudah bisa menigkatkan } \\
\text { ekonomi keluraga seperti tidak } \\
\text { hanya bergantung pada } \\
\text { pendapatan suami saja karena } \\
\text { sudah ada penghasilan sendiri } \\
\text { dari hasil produk yang dijual } \\
\text { bahkan sudah bisa menabung }\end{array}$ \\
\hline $\begin{array}{l}\text { Usaha yang dimiliki seperti ingin } \\
\text { terhenti karena kurangnya modal. }\end{array}$ & $\begin{array}{l}\text { Usaha yang dimiliki semakin } \\
\text { berkembang karena adanya } \\
\text { modal dari hasil pinjaman baik } \\
\text { dari Pemerintah, bank, swata, } \\
\text { maupun dari iyuran dan } \\
\text { kelompok simpan pinjam dalam } \\
\text { UPPKS Mekar Lestari }\end{array}$ \\
\hline
\end{tabular}

\section{KESIMPULAN}

Dari hasil hasil penelitian dan pembahasan yang peneliti dapatkan mengenai efektivitas Program Usaha Peningkatan Pendapatan Keluarga Sejahtera Kelompok Mekar Lestari Kecamatan Sekupang maka dapat diambil kesimpulan sebagai berikut: (1).Analisis dalam ukuran efektivitas berdasarkan pemahaman program menunjukan bahwa para penyelenggara sudah paham akan maksud dan tujuan dari dibentuknya program UPPKS, tapi masih 
kurangnya pemahaman dari pihak penyelenggara program yaitu anggota UPPKS, hal ini disebabkan masih kurangnya sosialisasi dari Penyelenggara kepada anggota kelompok penerima program UPPKS, dilihat dari analisis ukuran efektivitas pemahaman program belum dapat dikatakan efektif karena minimnya para anggota paham akan maksud dan tujuan program UPPKS; (2).Efektivitas berdasarkan ketepatan sasaran, tujuh puluh persen anggota UPPKS kelompok Mekar lestari adalah peserta Keluarga Berencana (KB), sedangkan 30\% persennya tidak ikut sebagai peserta KB dengan keterangan sudah lewat masa subur, dan ada yang belum menikah. Begitu juga rata rataanggota kelompok mekar lestari ini sudah mempunyai produk masing-masing meski sebagian masih mengikut atau belajar di kelompok untuk membuat usaha sendiri.Dan sebagian besar anggota kelompok masih dalam ekonomi menengah kebawah.Hal tersebut sesuai dengan ketentuan BKKBN yang menjadi sasaran utama program ini adalah peserta $\mathrm{KB}$ dan pengusaha yang sedang merintis usahanya serta mereka yang berada pada ekonomi menengah.Maka ukuran efektifitas dalam ketepatan sasaran sudah bisa dibilang efektif; (3). Efektifitas berdasarkan ketepatan waktu, dengan adanya kegiatan rutin di kelompok Mekar Lestari ini dan banyaknya kegiatan yang telah dilakukan seperti pelatihan keterampilan, bazar, kegiatan simpan pinjam, bahkan ikut majlis taklim bersama dan semua ini merupakan program dari awal kegiatan dan sudah terlaksana sesuai dengan rencana awal serta tidak mengganggu waktu pribadi para anggota. Maka analilis efektifitas dalam ukuran ketepatan waktu sudah bisa dibilang efektif; (4). Efektifitas berdasarkan tercapainya tujuan, dilihat dengan banyaknya Produk-produk yang dihasilkan, baik dalam bentuk makanan serta kerajinan-kerajinan seperti aksesoris dan juga program simpan pinjam yang telah berjalan dengan baik.Manfaat yang diperoleh oleh para anggota dan ketua kelompok mekar Lestari ini serta dengan berbagai lomba yang telah mendapat juara dan hal ini dibuktikan dengan sertifikat yang telah banyak dimiliki juga dengan tidak adanya kendala berarti maka ukuran efektifitas dalam hal Tercapainya Tujuan sudah efektif; dan (5). Efektifitas berdasarkan perubahan nyata, para ibu-ibu yang bergabung telah dapat mengembangkan usaha dari sebelumnya dan sudah dapat membantu ekonomi keluarga serta membantu anggota lainnya untuk mengembangkan usahanya masing-masing sudah dapat dikatakan efektif dalam hal analisis perubahan nyata karena banyak sekali memberikan dampak positif bagi anggota serta dilihat dari tiga indikator sebelumnya yang berjalan efektif dengan banyaknya perubahan yang dirasakan oleh anggota sejak bergabung dengan kelompok UPPKS ini. 


\section{REFERENSI}

Hikmat, Harry. 2010. Strategi Pemberdayaan Masyarakat. Bandung : Humaniora Utama Press.

Idrus, Muhammad. 2007. Metode penulisan Ilmu-Ilmu Sosial (Pendekatan kualitatif dan Kuantitatif). Yogyakarta:UII Press.

Kustriyadi, Heru. 2003. Perencanaan Keuangan Keluarga (Sebuah Langkah Menuju Keluarga Sejahtera). Jakarta: Salemba Empat.

Makmur. 2011. Efektivitas Kebijakan Kelembagaan Pengawasan. Bandung: Refika Aditama.

Makmur.2011. Efektivitas Kebijakan Kelembagaan Pengawasan. Bandung: Refika Aditama.

Moleong, Lexy, J. 2000. Metodelogi Penelitian Kualitatif. Bandung : PT.Remaja Rosdakarya.

Muhammad Safitra Arifin.2012.Efektifitas Pelayanan Publik di Kecamatan Maritengngae Kabupaten Sindenreng Rappang.Makasar : Universitas Hassanudin.

R.A. Supriyono. 2000. Sistem Pengendalian Menejemen.Yogyakarta: BPFE.

Silalahi, Karlinatawati. 2010. Keluarga Indonesia: Aspek dan Dinamika Zaman. Jakarta: Rajawali Pers.

Steers, Ricard M. 1986. Efektivitas Organisasi. Erlangga: Jakarta.

Sugiyono. 2010.Metode penelitian Kuantitatif Kualitatif. R\&D Bandung : Alfabeta.

Sugiyono. 2012. Memahami Penelitian Kualitatif. Bandung : Alfabeta.

Suyanto, Bagong. 2013. Anatomi Kemiskinan dan Strategi Penangannya.Malang : Intrans Publishing.

Yunus, Muhammad. 2008. Menciptakan Dunia Tanpa Kemiskinan. Jakarta: Gramedia Pustaka Utama.

Yunus. 2010. Pedoman Pemberdayaan Ekonomi Keluarga Bagi Pendamping UPPKS. Jakarta: BKKBN.

http://antarakepri.com/berita/20142/bkkbn-pamerkan-produk-uppks-di-batam-expo.

http://aplikasi.bkkbn.go.id/UPPKS/UPPKS/Report/RekapKesertaanBerKB.aspx.

http://repository.usu.ac.id/handle/123456789/29383.

http://www.bkkbn.go.id/dki_jakarta/index.php.

https://kepri.bps.go.id/index.php/linkTabelStatis.

https://kepri.bps.go.id/LinkTableDinamis/view/id/29.

https://id.wikipedia.org/wiki/Kota Batam. 
https://arsipskpd.batam.go.id/batamkota/skpd.batamkota.go.id/sekupang/profil/index. http://kepri.bkkbn.go.id/ViewProfil.aspx?ProfilID=20.

https://www.bkkbn.go.id.

www.pikas.bkkbn.go.id/ jabar/uppks.php. 